\title{
Construction of compiler technology course in application-based university
}

\author{
Wang $\mathrm{Na}^{1, \mathrm{a}}$, Zhang ShiMing ${ }^{1, \mathrm{~b}}$ \\ ${ }^{1}$ School of Computer and information, Shanghai Second Polytechnic University, Shanghai, 201209, \\ China \\ aemail: wnoffice@126.com, bemail: smzhang@sspu.cn
}

Keywords: compiler; construction; Application University; practice; theory

\begin{abstract}
Compiler technology course is a very important compulsory basic course in professional computer education, and it is also an important branch in the computer system software. But the value of compiler's existence as a classic core curriculum of computer science is to be questioned especially in some application university. Instead, they focus on the practice ability of mastering several languages and developing application systems. In our paper, we propose a new construction of compiler technology course which combine theory and practice and divide compiler into two levels: compiler technology and compiler theory.
\end{abstract}

\section{Introduction}

Our country has always attached great importance to education, economic and social development in our country critical time in education focus on the overall planning strategy, ahead of deployment to specify the way forward. 30 years of reform and opening up have been issued a "decision on education reform", "China Reform and Development Program ", "the decision on deepening reform of the decision to promote quality education" and other programmatic document, and promote education to a new level, new progress in education reform. At present, China is building a moderately prosperous society and accelerating socialist modernization critical period in the full implementation of the technology and education strategy, this strategy and the critical stage of the sustainable development strategy, the State Council promulgated and implemented "Education Plan ", will promote education in China in the new historical starting point to speed the reform and development, and better meet the new requirements of economic and social development and people's new expectations, with significant and far-reaching strategic significance.

Higher engineering education in China was mainly impacted by Europe before 1945, and followed the mode of former Soviet Union in the 20th century, end then influenced by the engineering education of United States after Chinese "reform and opening up". Today, China has become the world's manufacturing center. To make our country from large to strong, on one hand it should enhance the overall competitiveness of technology; on the other hand, training a large number of qualified engineers is the primary mission for higher engineering education in our country. The task should be done as soon as possible.

With the rapid development of higher education in our country, there has been a complete and special education system. In order to improve employee ratio, lots of university focus on meeting the direct requirements of enterprises. So engineering design and practice has been ignored seriously [2]. To main successful industrialization process in China, keep the sustainable development of national economy, and increase international competitiveness, it largely replies on engineers and technical experts at all levels [1]. Briefly, how to combine the theory with practice is the most urgent need for university education in our country.

\section{Compiler Technology Course}

Compiler technology course is a very important compulsory basic course in professional computer education, and it is also an important branch in the computer system software. The 
realization of any computer language can be separated from compiler technology. Therefore, as a student major in computer science, it is necessary to learn and master the basic structure and implementation techniques of the compiler for further learning, research and professional work.

But, considering current employment situation, the advantage of computer science students in the hardware and software knowledge and application ability is gradually weakened. When competing with students having specific applications and professional background, they face to increasing pressure. Even being employed, few people will engage in the research and development of compiler sys-tem. So the value of compiler's existence as a classic core curriculum of computer science is to be questioned. Especially in some application university, the practice ability of mastering several languages and developing application systems is most paid attention to. Actually, undergraduate education is to solve the students' basic professional ability, capacity for sustainable development which is the essence. The main teaching objective of compiler technology is making students re-understand algorithms and programs on the level of system to enhance the students' system capacity. It is the most difficult course in computer professional courses covering both formal language and abstract automata theory. It is also a comprehensive reflection of knowledge including data structure, programming languages, algorithms and software design. It effectively trains the abilities of calculated Thinking, algorithm design and analysis, program design and implementation (hardware and software), cognitive, analysis, development, and application of system.

\section{New Thought of Teaching Content Reform on Compiler Technology Course in Application-based University}

To meet the requirements of application in development of software industry, computer and science department of Shanghai second polytechnic University cooperates with several companies and dispatch students to practice there. The college's target is to cultivate practical software talents by practical teaching reform. New model is based on industry-university collaboration to foster high quality software talents. It has already trained a batch of software engineers who are quite welcomed by enterprises. But, the practices are usually aimed at courses like OOP, database, networks and so on. While other courses such as compiler technology which are theory-based are prevented from practice.

A. Cognize the importance of compiler technology

As teachers, we should enable students to understand that the compiler theory is the integration and practice of much curriculum knowledge which can further deepen the understanding on the basis of many professional courses. The principles, methods and techniques using in compiled translation program can help comprehend the essence of computer theory and play a significant role in the practical application of non-compiled system. Studying compiler technology favors the future work about software application, building language development platform, compiler system and even the operating system development.

B. Stimulate students' interest

Firstly, we start with the internal structure of the knowledge system to seize the internal relations and laws of the various functional stages of the compilation process, using meaningful questions to guide students' positive thinking. Disclose theoretical difficulties and abstract concepts in compiler theory by presenting problems to students. By answering questions from different perspectives, students can seek the principle and means to solve problems, thus guiding students to independently analysis and solve problem, deepening the understanding of compiler theory and technology.

Compiler technology is a strong theoretical course. In order to visualize abstract problems to facilitate students to understand and apply knowledge points, the use of multimedia tools can present principle knowledge in the form of animation, graphics to transform static to dynamic, teach through lively activities to stimulate students' interest in learning. The effect is as Fig.1. 


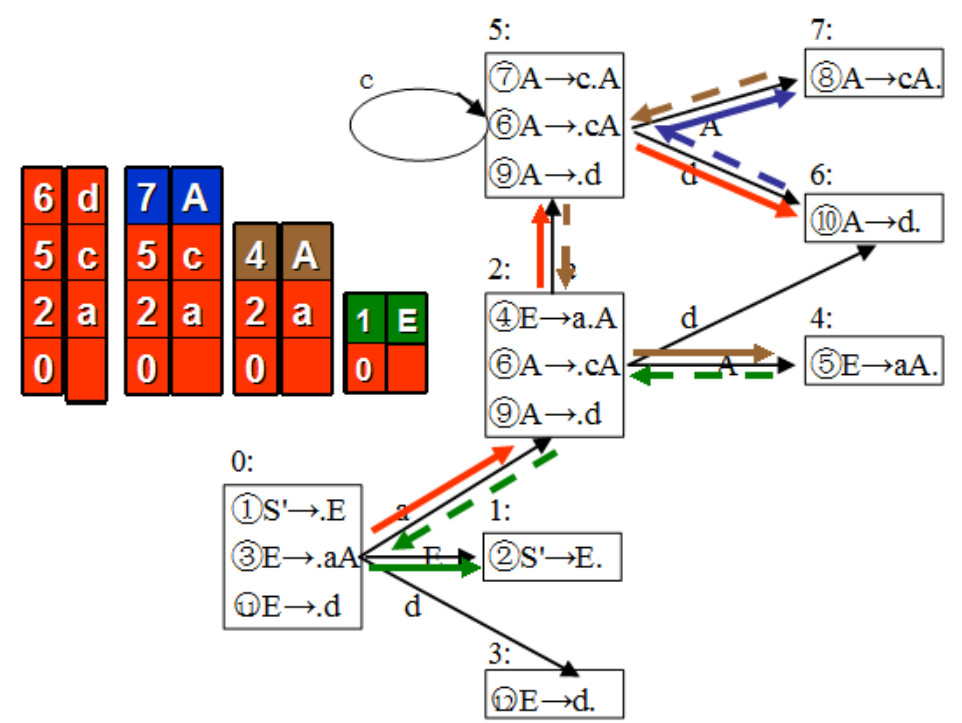

Fig.1. the multimedia interface of compiler technology course

C. Scientific curriculum development

According to the academic tenet of our school, we divide compiler into two levels: compiler technology and compiler theory. Compiler theory is set as an optional course emphasis on deep content introducing formalized principle for students interesting in compiler. While compiler technology introduced the basic methods and techniques to meet basic application and requires, then achieving the purpose of language transfer.

Teachers should insist on a combination of teaching and research, cite the latest scientific research and education reform into teaching and combine classical compiler theory with organically modern compiler technology. For example, we can introduce embedded compiler, distributed parallel compilers, and multi-core compiler to enrich compiler theory courses. In addition, we can also introduce the specific applications of compiler technology in artificial intelligent, parallel computing, and natural language processing to foreshadow the subsequent courses.

\section{New Thought of Teaching Method Reform}

\section{A. Web-based Teaching Method}

The Web-based Collaborative Teaching Model is the process of utilizing the computer network and multimedia technology to let different learners to interact and cooperate on the same learning content in order to make the students have a deeper understanding and better command of the courses. It intends to build a collaborative learning environment based on the computer network to make teachers and students, students and students to conduct collaborative learning on the basis of discussion, cooperation and communication.

If teacher clicks "Online Course" on the courseware of compiler technology, system will call the compiler technology programming teaching website automatically. It provides a wealth of teaching resources. To enhance the collaboration spirit among students, facilitate the communication between teachers and students, we developed the collaborative learning forum of compiler technology courses with fast and friendly interface.

B. projects-based experiments

The two types of projects are validation experiments and comprehensive experiments. The former is tied in with the content of classroom instruction that is compiled by teachers according to the original rationale taught order to sync certain confirmatory experimental subject, allowing students to complete related sub-module one by one, and gradually expanding to improve the entire compiler. The step-by-step method not only increases the sense of accomplishment and self-confidence of the students, but also enables them to develop a solid basis. It can also stimulate 
students' interest and enthusiasm in learning.

Certain scale comprehensive design experiment is essential to ensure the effect of practice. We design projects about compiler technology programming carefully. Students will be divided into several groups according to students and their topics of interest. Students selected the leader of each team. Each leader is equivalent to project manager, and is responsible for the entire software project organization and coordination. Each member should put forward their own ideas and views of other team members to evaluate by listening to special reports, documentation, inspection, such as aspect, and then by the team leader determine the group's research projects.

In actual Operation, according to the stage of validation experiments, the students were divided into different levels of the small group and they select different experimental topics suitable for their level. Each group follows the complete compiler development integrating the software engineering thinking. In this way, each student gets experience from analysis, design, coding, testing and maintenance of the software development process. Meanwhile, they improve their engineering and team awareness.

In the end of the experiment, teacher lets each student display experimental results and makes open reply to give a fair rating.

\section{Conclusion}

Today, teachers should pay much attention to teaching methods, adopt new effective methods and make good use of internet to improve the teaching quality. By summing up the teaching reform of compiler technology, our team is going to change the traditional teaching mode. Web-Based teaching method and project-based experiments will put into practice to solve realistic problems such as lack practice of theory-based course. Teachers use flexible methods to induct content and lead students to think, discover and practice by themselves. Through several years' experience, students can not only master principle theories in compiler technology but also complement a compiler in groups. The new course reform combines theory with practice that enhances theory level in Shanghai second poly-technic university and will help students' deep development in relative profession.

\section{Acknowledgement}

This work is supported by Academic Affairs Division of Shanghai Second Polytechnic University and special funds of 085 . We also thanks for the discussing and instruction of department chairman Zhang ShiMing.

\section{References}

[1] Yang Dongyong. Return to Engineering: Education Reform to foster Applied Innovative Software Talents. Proceedings of 2009 4th International Conference on Computer Science \& Education. 2009

[2] Wu Qidi. Reform and Development of China Higher Engineering Education[J]. China Higher Education Evaluation. 2007(4): 3- 7

[3] Zhang Chengcheng, Guo Shiying. A survey on the outline of National Long-Term Education Reform and Development Plan. Communication Software and Networks (ICCSN). 2011

[4] Dong, Hong, Zhang, ChuanYin. Discussions on the reform of higher vocational education from training the IT students’ occupational ability. E-Business and E -Government (ICEE). 2011

[5] Ming Xiao, Guang Hu. Research on Reform of Computer Elementary Education in University. Education Technology and Computer Science (ETCS). 2010 